\title{
Effect of Mode of Delivery on Children Intelligence Quotient at Pre-School Age in El-Minia City
}

\author{
Magda F. Hasab Allah, Ahmed R. El Adawy, Manal F. Moustafa, Hala A. Ali \\ Faculty of Nursing - Minia University. \\ Faculty of Medicine - Minia University. \\ Faculty of Nursing - Assiut University.
}

\begin{abstract}
:
Background: There has always been an asking question with obstetricians and health staff whether delivery mode can affects child intelligence. This study was conducted to compare the intelligence quotient (IQ) of pre-school aged children delivered by cesarean section (C.S) and spontaneous vaginal delivery (S.V.D) in Minia city. Aim of the study: to determine effect of mode of delivery on children IQ at pre-school age in Minia city. Materials and Methods: structured interviewing sheet including: Socio-demographic data such as (mother's age, level of education, etc), obstetrical history including (Number of deliveries, duration of labor, etc), Child history including (gestational age of the child/ week, birth weight / Kg, etc). And "Good enough \& Harries" intelligence test were used. Design: Cross sectional descriptive research design. Setting: data were collected from Nursery schools in Minia City. Sampling: Three hundreds children were included in this study; they were divided into two groups (150 children delivered by S.V.D and 150 children delivered by C.S). Results: The study results revealed that there are no statistically significant differences between children IQ scores based on mode of delivery at $(\mathrm{P}<0.05)$. On the other hand by using other advanced statistical technique called "stepwise regression" having the ability to determine variables which can predict the children IQ, in this study it was found that we can predict children IQ through three variables which are: S.V.D that was related to higher IQ scores, mother's age and number of deliveries in a direct negative relation at $(\mathrm{P}<0.05)$. Conclusion \& recommendations: Based on our findings, the association between cesarean deliveries with better cognitive development in children cannot be supported.
\end{abstract}

\section{Keywords: Mode of delivery, IQ (Intelligence Quotient)}

\section{Introduction}

The process of labor involves more than the birth of a newborn. Numerous physiological and psychological events occur that ultimately result in the birth of a newborn and the creation or expansion of the family. Labor is a complex multifaceted interaction between the mother and fetus. It is a series of processes by which the fetus is expelled from the uterus. It is difficult to determine exactly why labor begins and what initiate it. Although several theories have been proposed to explain the onset and maintenance of labor, none of these has been proved scientifically .(Gilbert, 2007).

It is widely believed that labor is influenced by a combination of factors including uterine stretch, progesterone withdrawal, increased oxytocin sensitivity, and increased release of prostaglandins. In recent years, cesarean rate was increasing in the world (Meikle, et al.2005; Angeja, et al. 2006 ; Faisal- cruy and Rossimenezs, 2006).

There has always been an asking question with obstetricians and health staff whether delivery mode can effect on children intelligence; Despite the lack of evidences in relationship between delivery mode and children's intelligence quotient (IQ), this belief was common between many people and also many obstetricians and health staff that brain and cognitive function of children are negatively affected

by pressures during passing the birth canal (normal vaginal delivery) and birth traumas (Khadem and Khadivzadeh, 2010)

The word intelligence is as old as human existence and symbiotically associated with thinking skills that distinguish an individual from another and most importantly a predictor of life adjustment in the society. Anyone who scores low on the scale of cognitive intelligence otherwise known as intelligent quotient is taken to be a low achiever, dull, indolent, stupid and grossly maladjusted. However, psychologists have identified many more areas of intelligence apart from the original one (cognitive intelligence), which include: fluid intelligence, crystallized intelligence, social intelligence, emotional intelligence, spiritual intelligence, financial intelligence, etc. which are all indices of adjustment (Zohar \&Marshall, 2000; Animasahun, 2003; Jimoh, 2007).

Intelligence quotient (IQ) tests attempt to measure innate cognitive ability and future potential. Although they are not immune to the influence of past experience, a score on an IQ test can only ever be a 'snapshot', a picture of strengths and difficulties

Vol (1), No (1), June 2013 
that can change for better or worse. Performance on an intelligence test relies on a complex range of cognitive functions, or mental processes (Semel, et al. 2000).

An intelligence test (IQ test) is by definition, any test that purports to measure intelligence. Generally such tests consist of a series of tasks, each of which has been standardized with a large representative population of individuals. Such a procedure establishes the average IQ as 100 (John \& Sons, 2002). The appropriate use of IQ tests provides information about a child's ability to perform under controlled circumstances. Used thoughtfully, they give a snapshot of current strengths and weaknesses and suggest possible strategies for support and intervention. But IQ reports that fail to consider the child's social and medical history, linguistic and cultural background, ability to plan and organize his or her behavior, enthusiasm, impulsivity, anxiety and persistence reveal more about the person testing than the child. IQ should be viewed in the context of the individual as a whole. Of course, a high IQ does not guarantee future success in examinations or life in general, but it can clearly be helpful. Hard work and application skills are just as important, if not more so, especially as the child progresses through the education system and into adulthood (Semel, et al. 2000). Intelligence is the capacity to learn or understand. Although intelligence is possessed by all people, it varies in amount for each person and remains the same throughout life from approximately 18 years of age. In psychology, intelligence is defined as the capacity to acquire knowledge or understanding, and to use it in novel situations. IQ is the abbreviation for intelligence quotient. Intelligence quotient (IQ) is an age-related measure of intelligence and is defined as 100 times mental age. The word 'quotient' means the result of dividing one quantity by another, and intelligence can be defined as mental ability and quickness of mind (Stemberg \& Detterman, 2002).

Pre-school-age children who are experiencing delays in physical, cognitive, communication, social, emotional, or adaptive development are often referred for a comprehensive assessment to make diagnostic determinations and to help develop appropriate interventions. Typically cognitive assessment has a key role in a comprehensive evaluation of a young child. Preschool assessment takes places for many reasons: screening, diagnosis, placement decisions, and remediation of problems. Research has shown that early intervention in a child's life is necessary to minimize lasting effects of a child's difficulties. Thus, a comprehensive cognitive assessment in the pre-school years can be a key component of a thorough multidisciplinary evaluation that directly leads to intervention strategies (Kanny \& Culbertson, 2003).

Through lines and symbols drawn on paper, children express many emotions and thoughts that they would not be able to express verbally. In addition to children's intelligence and personality traits, their interaction with the environment and daily experiences make their lines and symbols unique to themselves (Yavuzer, 2000).

\section{Significance of the study:}

Education is one of the most aspects of human resource development; every child should have the opportunity to achieve his or her academic potential. It is generally noticed that at least $20 \%$ of children in classroom get poor marks. Poor school performance should be seen as "symptom" reflecting a larger underlying problem in children, this symptom may not only result in the child have low self esteem, but also can cause significant stress to the parents (Karande \& Kulkarni, 2005).

Because of increasing high trend in cesarean delivery mode in our country together with this belief that it can result in more child intelligence, this study was conducted and carried out to determine and compare the intelligence quotient of pre-school age children delivered by C.S. and S.V.D. in Minia city.

\section{Subject and methods:}

The aim of the present study was to determine effect of mode of delivery on children intelligence quotient at pre-school age in Minia city.

I. Research Design: Cross sectional descriptive research design was utilized in this study.

\section{Subjects:}

II. Setting: This study was carried out in all nursery schools in Minia city. Each nursery school is divided into two sections: the 1st section contains a garden for entertainment and playing where mothers deliver their children to their teachers and play with them for minutes before leaving them. And the 2nd section contains classes for teaching where children receive their lessons. About nursery schools (kindergartens) which were visited to collect the data were as following: Monazamet El-Shabab, San Mark, Al-Hoda, Nour El- Bayan, El- Moasasa and all of them contains 4 classes, two classes for $\mathrm{KG} 1$ and the other two classes for KG2 each class contains about 25 children. And El- Lamati primary school, Shalabi primary school, and El- Salam primary school contain 2 classes, one class for KG1 and the other for $\mathrm{KG} 2$ and also each class contains about 25 children.

III. Sample: After exclusion of children who didn't match the inclusion criteria of this study and who attended to the nursery school with their fathers or brothers not with their mothers, the sample was 
consisted of 300 children randomly selected divided into 150 children delivered by S.V.D and the other 150 children delivered by C.S.

\section{Inclusion criteria:}

1. Maternal age was within the reproductive age (20-45 years).

2. Pre-school age children ( 4.5 to $<6$ years)

3. (S.V.D) and (C.S.) delivery.

4. Birth weight was $2.5 \mathrm{Kg}$ and more.

5. Duration of labor within 24 hours.

\section{Exclusion criteria:}

1. Twins

2. Children suffering from any disease, especially neurological diseases such as meningitis, fever, convulsions, or brain trauma.

3. Duration of labor more than 24 hours.

4. Instrumental delivery (Ventouse, Forceps).

5. Maternal diseases during pregnancy especially ante partum hemorrhage, hypertension, D.M., anemia, and H.D.

IV. Tools for Data Collection:

Two tools were used in this study:

1. Structured interviewing sheet: It was developed by the researcher to collect the data related to the mothers and children history. The structured interviewing sheet includes the following data:

(Part1) Data related to the mothers including:

a. Socio-demographic characteristics of the studied sample: This includes mothers (Age, level of education, occupation, and residence).

b. Data about their obstetrical history: This includes (number of deliveries, number of abortions, mode of delivery, sex of the child, duration of delivery/hours and any intrapartum complications).

(Part2) Data related to the children history: Includes (age of the child/ months, gestational age of the child at birth/weeks, birth weight/ $\mathrm{Kg}$, and any intrapartum complications (hypoxia, cyanosis or external injuries) occurred for the child.

Note: gestational age of the child was collected from the mothers (some of them told the age in months and others in weeks so all of them were transferred to weeks).

The second tool was the scale which measures the children intelligence. In this study the researcher used "Good enough \& Harries" intelligence test which consists of 77 items.

\section{Test description:}

This test was developed by "Good enough" in 1926 to measure the intelligence of the children at the age of kindergartens up to the age of 15 years, it was composed of 51 items in which the researcher instruct the children to draw the best of what they can of a picture of a man so it is also called "Man Draw Test". (Farag, 1989)

Then "Harries" in 1963 modified the test of "Good enough" to be composed of 77 items instead of 51 items and became called "Good enough \& Harries". (Abu Elella, 1976 ). Adaptation was done on this test by Fouad, (1991) based on the same 77 items of "Good enough \&Harries" he could categorize the given raw IQ scores to determine the child IQ level, each score meets one of the following levels of intelligence $(\mathbf{0 - 4}=$ low IQ, 5-13= middle IQ, 14-17= good IQ, 18-26= high IQ, and 27 or more $=$ genius).

Test instructions:

Instructions of the test were given orally in the form of assignment of the studied sample to exclude what might exist in front of them on the desk, except for a white paper and a pencil, so the examiner asked the children to draw the best of what can be of a portrait of a man after filling the identification data which was represented in the child's name, age, and school.

This test depends on the principle of the child's ability to perform mental concepts and perceptions appears on his drawing an image of a man including details about body parts and body proportions, also including clothing. Technical considerations and graphic quality doesn't interfere with the score of the test.

\section{Correction of the test:}

Correction of the test carried out by giving the child a single degree for each item on the graph of the 77 items in the scale, and then calculates the total raw score obtained by the child. Then we could determine the IQ of the children through the previous scale used and adapted by Fouad (1991) by which he can determine the IQ of the child immediately after calculating raw score which meets one of the levels of intelligence discussed before.

\section{Ethical considerations:}

Before the implementation of the study an official permission was obtained from the director of each nursery school in Minia city and from mothers of the children after full explanation of the research idea, the procedure and rights for privacy and confidentiality.

\section{Procedure:}

- Data were collected from 8 nursery schools in Minia city; from about 13 classes for children aged from 4.5 to less than 6 years (the age before school entry (KG2). Each class contains on average 25 children, not all of them were included in the sample but they were selected randomly according to inclusion and exclusion criteria of this study. Three days /week, each day 
the intelligence quotient (IQ) of about 5 children was measured, the test required about 10-15 minutes for the child to draw the graph, and about 10-15 minutes for the researcher to correct the test and determine the child IQ.

- Nursery schools were visited at 8.00 am to meet the mothers while they bringing their children to the school, they were met before measuring child IQ to determine if the child included or excluded from the study.

- The researcher greeting the mother and introduces herself, then explains the nature of the study \& its aim.

- After taking the oral consent from the mother, she was given full explanation of the procedure, and rights for privacy and confidentiality.

- Interviewing the mother to collect the data related to socio-demographic characteristics, obstetric, and child history. Each interview takes about 10 minutes to fill the data in the sheet.

- The last step was meeting the child to measure the IQ level by applying the IQ test then determines the IQ level.

\section{Statistical analysis:}

Data were analyzed using the statistical package for social science (SPSS) version 11.5 (Windows Microsoft). Continuous data were expressed as frequency, percentage, mean, S.D, and the range. Discrete data were expressed as frequency and percentage. Comparison between variables was done using chi-square test, T. test and Stepwise regression. The last test was used to identify variables that could be predictors of the children intelligence; one advantage of this test was it can predict accurately what variable affecting IQ first then identify the following variables which affect IQ, etc. so it was done on multi stages to determine in priority the most powerful variable which could predict the children IQ then the following variables in sequence, it calculates the correlation coefficient $\left(\mathbf{R}, \mathbf{R}^{\mathbf{2}}\right.$ ) between the variable and the IQ, then calculates the contribution percentage and at the end calculate the prediction equation that was used to calculate the $P$. value which may be in positive or negative signal, positive signal means direct positive relation (the increase in the independent variable leads to the increase of the dependent variable), and the negative signal means direct negative relation (the increase in the independent variable leads to decrease in the dependent variable) and vice versa. Probability ( $P$.value) less than 0.05 was considered significant and less than 0.001 was considered highly significant.

\section{Result:}

Table (1): Socio- demographic characteristics of women in the study sample.

\begin{tabular}{|c|c|c|}
\hline Items & No. & Percent $(\%)$ \\
\hline \multicolumn{3}{|l|}{ Mother's age/years } \\
\hline - 20-25 years & 42 & 14.0 \\
\hline - 25-30 years & 170 & 56.7 \\
\hline - $\quad$ More than 30 years & 88 & 29.3 \\
\hline Mean \pm S.D & \multicolumn{2}{|c|}{$(28.36 \pm 4.047)$ years } \\
\hline Range & \multicolumn{2}{|r|}{$(21-39)$ years } \\
\hline \multicolumn{3}{|l|}{ Education } \\
\hline - $\quad$ Illiterate & 15 & 5.0 \\
\hline - $\quad$ Primary & 2 & 0.66 \\
\hline - $\quad$ Preparatory & 12 & 4.0 \\
\hline - $\quad$ Secondary or equal & 212 & 70.67 \\
\hline - $\quad$ University and high studies & 59 & 19.67 \\
\hline \multicolumn{3}{|l|}{ Occupation } \\
\hline - Working & 64 & 21.3 \\
\hline - $\quad$ Housewife & 236 & 78.7 \\
\hline \multicolumn{3}{|l|}{ Residence } \\
\hline - Urban & 300 & 100 \\
\hline
\end{tabular}

No. $=$ number or frequency 
Table (2): Obstetric history of women in the study sample ( $N=300)$ :

\begin{tabular}{|c|c|c|}
\hline Items & No. & $\%$ \\
\hline \multicolumn{3}{|l|}{ Number of Deliveries } \\
\hline - $\quad$ Once & 12 & 4 \\
\hline - $\quad$ Twice & 188 & 62.7 \\
\hline - $\quad$ Three times & 80 & 26.7 \\
\hline - $\quad$ More & 20 & 6.6 \\
\hline Mean \pm S.D & \multicolumn{2}{|c|}{$2.36 \pm 0.66$} \\
\hline \multicolumn{3}{|l|}{ Number of abortions } \\
\hline - $\quad$ Once & 90 & 30 \\
\hline - $\quad$ Twice & 13 & 4.33 \\
\hline - $\quad$ More & 1 & 0.33 \\
\hline - $\quad$ None & 196 & 65.34 \\
\hline Mean \pm S.D & \multicolumn{2}{|c|}{$3.01 \pm 1.37$} \\
\hline \multicolumn{3}{|l|}{ Mode of delivery } \\
\hline - $\quad$ Spontaneous vaginal delivery (S.V.D) & 150 & 50 \\
\hline - Cesarean section (C.S) & 150 & 50 \\
\hline \multicolumn{3}{|l|}{ Causes of Cesarean section $(\mathrm{N}=150)$} \\
\hline - $\quad$ Cephalo-pelvic disproportion & 78 & 52 \\
\hline - Breech presentation & 27 & 18 \\
\hline - Post date & 10 & 6.7 \\
\hline - Placenta previa & 8 & 5.3 \\
\hline - Premature rupture of membranes (PROM) & 2 & 1.3 \\
\hline - Unknown causes & 25 & 16.7 \\
\hline \multicolumn{3}{|l|}{ Duration of delivery/hours } \\
\hline - $\quad$ Normal (during 24 hours) & 300 & 100.0 \\
\hline
\end{tabular}

Table (3): Characteristics of the children:

\begin{tabular}{|c|c|c|}
\hline Item & No. & $\%$ \\
\hline \multicolumn{3}{|l|}{ Age of the child/months } \\
\hline - $54->60$ & 2 & 0.7 \\
\hline - $60->66$ & 198 & 66 \\
\hline - $66-71$ & 100 & 33.3 \\
\hline Mean \pm S.D & \multicolumn{2}{|c|}{$(64.55 \pm 2.78)$ months } \\
\hline Range & \multicolumn{2}{|c|}{ (57-71) months } \\
\hline \multicolumn{3}{|c|}{ Gestational age of the child at birth/weeks: } \\
\hline - 35 & 2 & 0.7 \\
\hline - 36 & 31 & 10.3 \\
\hline - 37 & 229 & 76.3 \\
\hline - 38 & 26 & 8.7 \\
\hline $\begin{array}{l} \\
\end{array}$ & 11 & 3.7 \\
\hline $\begin{array}{ll}-40 \\
\end{array}$ & 1 & 0.3 \\
\hline Mean \pm S.D & \multicolumn{2}{|c|}{$(37.05 \pm 0.62)$ weeks } \\
\hline Range & \multicolumn{2}{|c|}{ (35-40) weeks } \\
\hline \multicolumn{3}{|l|}{ Sex of the child } \\
\hline - $\quad$ Male & 136 & 45.3 \\
\hline - $\quad$ Female & 164 & 54.7 \\
\hline \multicolumn{3}{|l|}{ Birth weight/Kg } \\
\hline - $\quad \operatorname{Normal}(>2.5 \mathrm{Kg})$ & 300 & 100.0 \\
\hline
\end{tabular}


Table (4): Characteristics of children according to their intelligence quotient (IQ) scores ( $N=300$ ).

\begin{tabular}{c|c|c}
\hline \multicolumn{2}{l|}{ Item } & No. \\
\hline \multicolumn{2}{l|}{ Intelligence quotient (IQ) scores } \\
\hline$\bullet \quad$ Low (0-4) & 40 & 13.3 \\
\hline$\bullet \quad$ Middle (5-13) & 195 & 65 \\
\hline$\quad$ Good (14-17) & 41 & 13.7 \\
\hline • High (18-26) & 24 & 8 \\
\hline Mean \pm S.D & & $9.53 \pm 4.71$ \\
\hline
\end{tabular}

Table (5): Relationship between children IQ and mode of delivery, mother's age and number of deliveries: ( Stepwise regression)

\begin{tabular}{|c|c|c|c|c|c|c|c|c|c|}
\hline & Variable & $* R$ & $* R^{2}$ & Contribution & $F$ & $P$. & $B$ & Const. & $\begin{array}{l}\text { Predictor } \\
\text { equation }\end{array}$ \\
\hline Step_1 & $\begin{array}{l}\text { Mode of } \\
\text { delivery } \\
\text { (spontaneous } \\
\text { vaginal } \\
\text { delivery) }\end{array}$ & 0.797 & 0.636 & $63.6 \%$ & 518.93 & $0.001 * * *$ & 0.797 & 5.799 & $\begin{array}{l}\mathrm{IQ}=5.799+0.797 \\
\text { mode of delivery }\end{array}$ \\
\hline \multirow{2}{*}{ Step_2 } & $\begin{array}{l}\text { Mode of } \\
\text { delivery(S.V.D) }\end{array}$ & \multirow{2}{*}{0.807} & \multirow{2}{*}{0.652} & \multirow{2}{*}{$65.2 \%$} & \multirow{2}{*}{277.07} & \multirow{2}{*}{$0.001 * * *$} & 0.821 & \multirow{2}{*}{9.902} & \multirow{2}{*}{$\begin{array}{l}\mathrm{IQ}=9.902+0.821 \\
\text { mode of delivery } \\
-0.128 \text { mother } \\
\text { age }\end{array}$} \\
\hline & Mother's age & & & & & & $\overline{-} \mathbf{0 . 1 2 8}$ & & \\
\hline \multirow{3}{*}{ Step_3 } & $\begin{array}{ll}\text { Mode } & \text { of } \\
\text { delivery } & \\
\text { (S.V.D) } & \end{array}$ & \multirow{3}{*}{0.812} & \multirow{3}{*}{0.659} & \multirow{3}{*}{$65.9 \%$} & \multirow{3}{*}{189.69} & \multirow{3}{*}{$0.001 * * *$} & 0.817 & \multirow{3}{*}{8.356} & \multirow{3}{*}{$\begin{array}{l}\mathrm{IQ}=8.356+ \\
0.817 \text { mode of } \\
\text { delivery }-0.122 \\
\text { mother age }+ \\
0.083 \text { number of } \\
\text { deliveries }\end{array}$} \\
\hline & Mother's age & & & & & & $\begin{array}{l}- \\
0.122\end{array}$ & & \\
\hline & $\begin{array}{ll}\begin{array}{l}\text { Number } \\
\text { deliveries }\end{array} & \text { of } \\
\end{array}$ & & & & & & $\begin{array}{l}- \\
0.083\end{array}$ & & \\
\hline
\end{tabular}

Statistically significant at $\mathrm{p}<0 .{ }^{*} \mathrm{R}=$ Correlation Coefficient 5 


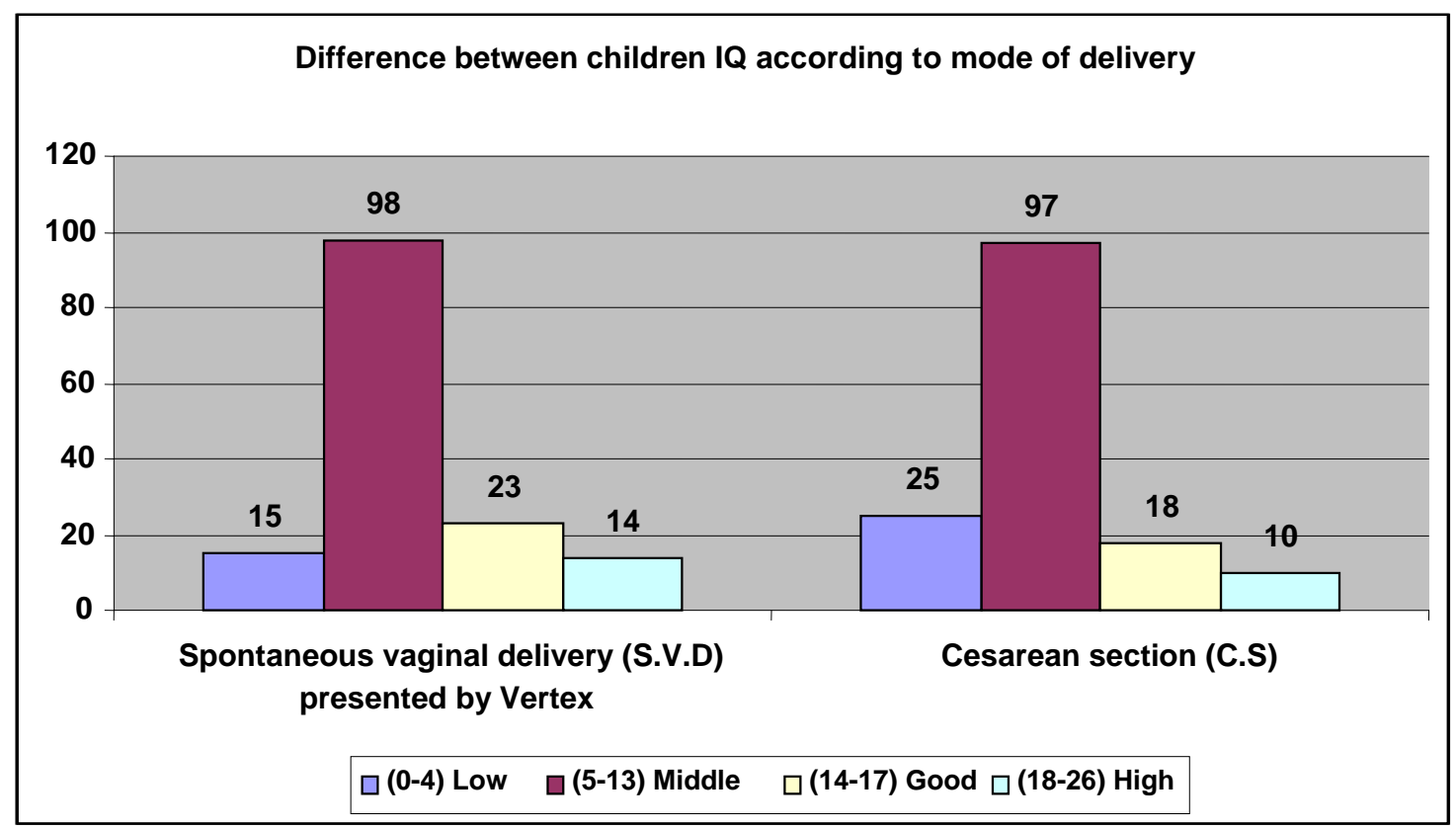

Figure (1): Difference between children IQ according to mode of delivery.

Statistically significant at $\mathrm{p}<0.05$

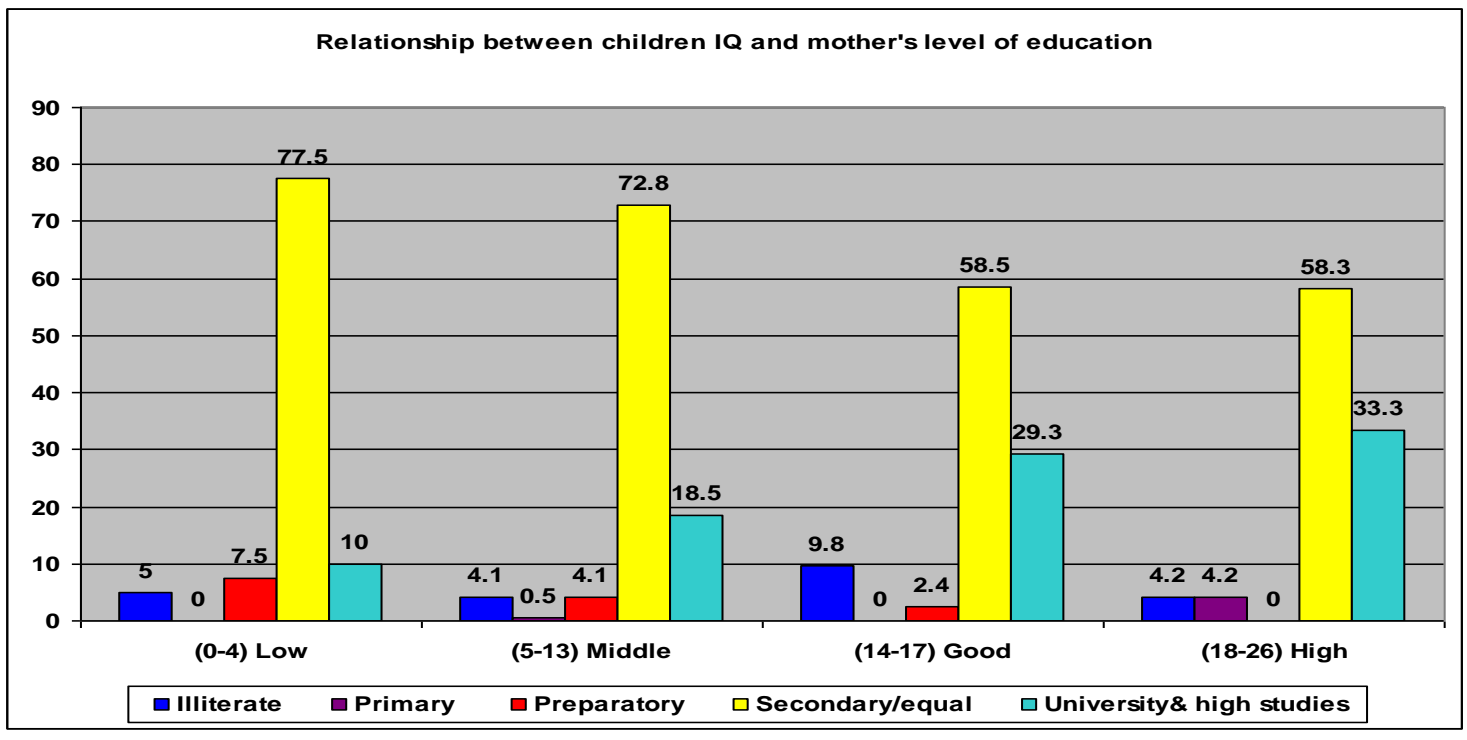

Figure(2) :Relationship between children's IQ and mother's level of education Statistically significant at $p<0.05$ 


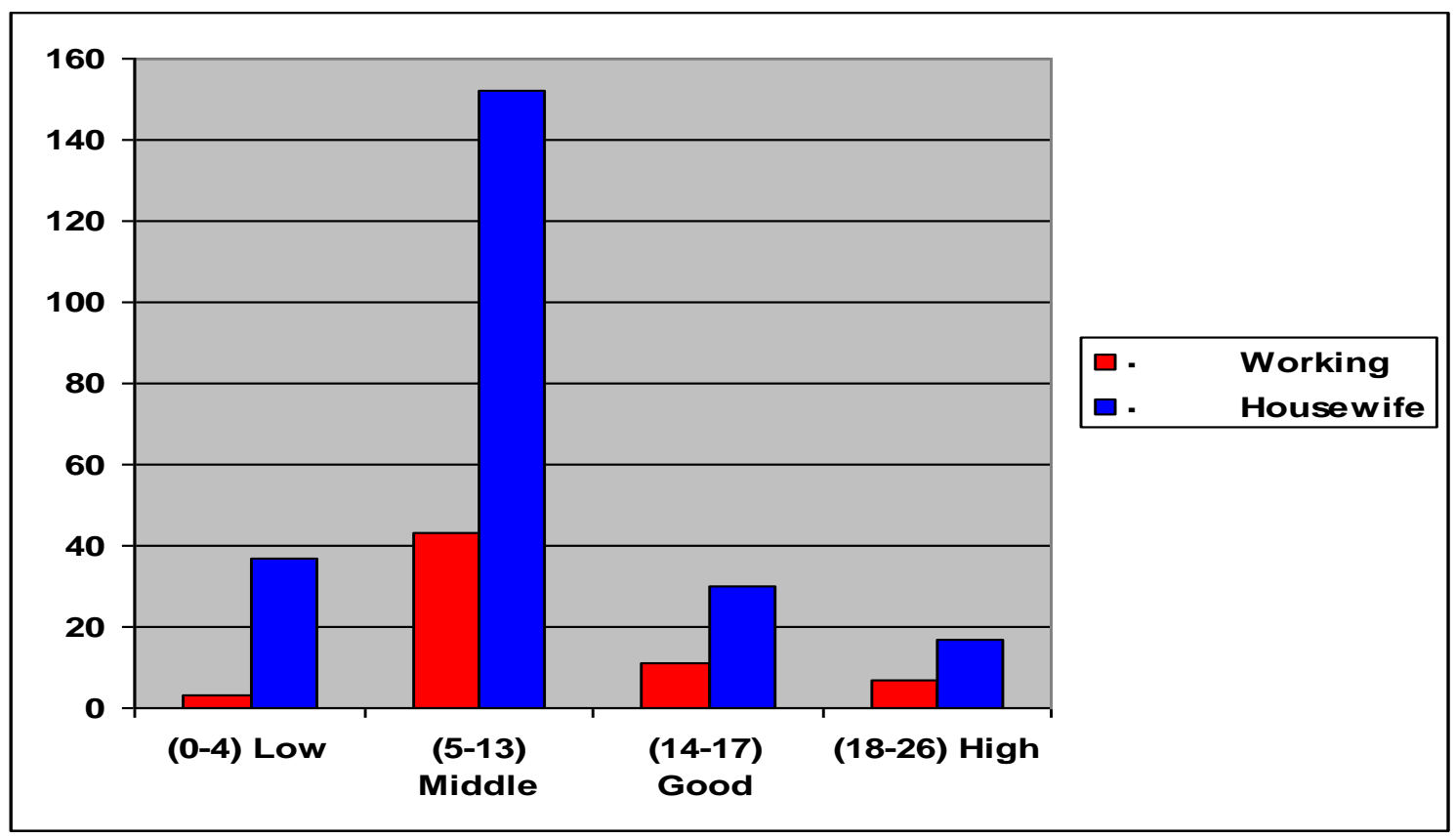

Figure 3. Relationship between children IQ and mother's occupation

Table (1): shows the distribution of the sample according to socio demographic characteristics in which it was found that the mean age of the mothers was $(28.36 \pm 4.047$ years $)$ ranging from (21 to 39 years). Only $(5 \%)$ of mothers were illiterate. Concerning the mother's occupation only $(21.3 \%)$ of mothers was working. All of women $(100 \%)$ included in the sample were selected to be lived in urban areas.

Concerning obstetric history,

Table (2) indicates that the majority of the mothers (62.7\%) had experienced two times of deliveries if compared with (4\%) only who had one delivery. Nearly two thirds of the women $(65.34 \%)$ didn't experience abortion. Regarding mode of delivery half of the women $(50 \%)$ delivered by cesarean section, while $(50 \%)$ delivered through spontaneous vaginal delivery. About causes of delivery by cesarean section (C.S), nearly more than half of the mothers (52\%) had C.S as a result of cephalo-pelvic disproportion, while PROM represented only (1.3\%). As regard duration of delivery/ hours, all women (100\%) included in this study were delivered within normal range of hours (within 24 hours).

Concerning child history characteristics,

Table (3) shows that around two thirds of the children $(66 \%)$ were within the age group (60->66 months) or ( 5 to less than 5.5 years). Only $(0.7 \%)$ was within the age group (54->60 months) or (4.5 to less than 5 years). More than two thirds of the children $(76.3 \%)$ were delivered on a gestational age of 37 weeks, a little ratio $(0.3 \%)$ were delivered on a gestational age of 40 weeks. As regard the sex of the baby more than half of the sample children (54.7\%) were females, but males represented (45.3\%). By looking to birth weight, all children selected in the sample $(100 \%)$ were delivered within normal birth weight $>2.5 \mathrm{Kg}$.

Table (4) indicates the relationships between children IQ and mode of delivery, mother's age and number of deliveries. In which there were high statistical significant differences between children IQ and mode of delivery, mother's age, and number of deliveries $(P=0.001)$ respectively, in which mode of delivery (spontaneous vaginal delivery), had direct positive relation on children IQ. On the other hand there was direct negative relation between mother's age and children IQ (the higher mother's age the lowest child IQ). Also there was direct negative relation between number of deliveries and children IQ (the higher number of deliveries the lowest children IQ).

Stepwise Regression was used to know which the strongest variables which predict children IQ, here variables that were found to be predictors of children IQ were mode of delivery represented the first variable that could predict child IQ, the second step determined the next variable which predicts children IQ that follow the first variable and the third step determine also the next variable that follow the second variable to predict children IQ. At the same time, the test excluded the variables automatically which couldn't predict children IQ such as number of abortions.

Concerning characteristics of children according to their IQ it was found About two thirds of the children $(65 \%)$ had middle IQ level with score 
(5-13), only (8\%) of the children had high IQ level with score (18-26).

As shown in Figure (1) there were no statistical significant differences $(P=0.286)$ between children IQ scores according to the mode of delivery.

As shown in figure (2) there were no statistical significant difference between children IQ scores according to mother's level of education $(P=0.130)$.

As shown in figure (3) there was statistical significant difference between children IQ scores and mother's occupation $(P=0.05)$.

Table (5) indicates the relationships between children IQ and mode of delivery, mother's age and number of deliveries. In which there were high statistical significant differences between children IQ and mode of delivery, mother's age, and number of deliveries $(P$ $=0.001)$ respectively, in which mode of delivery (spontaneous vaginal delivery), had direct positive relation on children IQ. On the other hand there was direct negative relation between mother's age and children IQ (the higher mother's age the lowest child IQ). Also there was direct negative relation between number of deliveries and children IQ (the higher number of deliveries the lowest children IQ).

\section{Discussion:}

Birthing is a natural process; the process of birth involves passage of the baby's head through the mother's bony pelvis. In order to easily navigate this area the infant's head must move in just the right way. This involves forward bending of the head and neck to get into the pelvis, rotation (to one side) to get through it, and then backward bending to finally exit the birth canal. Operative delivery is to be considered only when there are clinical or justifiable indications for such a procedure. (18).

The aim of the present study was to determine effect of mode of delivery on children IQ at pre-school age in Minia city.

The results of this study discussed within the frame of the references that study the effect of mode of delivery on children IQ.

Regarding mother's educational level in this study, $(70.67 \%)$ of the women was secondary school or equal. Also about (19.7\%) were university and high studies. The rest of the sample distributed in a little percentage between who were illiterate $(5 \%)$, primary $(0.66 \%)$, and preparatory education $(4 \%)$. This came in accordance with the study of Khadem., (5) who stated that about $(6.61 \%)$ only of the studied sample were uneducated, in the same time primary education represents (6.45\%), guidance school $(12.21 \%)$, high school $(15.12 \%)$, associate degree $(14.58 \%)$, and Bachelor of Science and more representing $(15.52 \%)$.
Concerning maternal residence (100\%) of women included in the sample were living in urban area to have the same living circumstances, opportunities in education and the same water supply than when the sample taken from rural and urban areas in which there are differences in every thing that could be a contributing factor to affect children intelligence. This results agreed with the study of Tork (19) who reported that there was a reason to expect that the place of living might affect IQ scores since a previous study has shown that at least a half century ago, children from rural areas scored slightly lower on intelligence tests than children grown up in large cities.

Concerning table (2) showing obstetrical history, about $(62.7 \%)$ of the women had two times delivery, in the same time $(65.34 \%)$ of the women had no abortions. In relation to mode of delivery, the present study consisted of 300 children, divided into 150 children representing (50\%) were delivered through S.V.D including whose deliveries assisted with episiotomy. And the other 150 children also representing (50\%) were delivered through C.S. This came in the same line with the study of Khadem ( 5), in his study the studied sample was divided into 189 children $(50 \%)$ were delivered through natural vaginal delivery and another 189 children (50\%) were delivered through cesarean section. Then calculating the mean and standard deviation of the IQ scores of both groups then comparing between both.

Regarding duration of delivery taken per hours, also (table 2) revealed that all women included in the sample $(100 \%)$ delivered within 24 hours (it was estimated that normal time taken in normal labor didn't exceed 24 hours from the start of true labor pain) to exclude the possibility of prolonged labor to be the cause of lowering children IQ level. This findings was in agreement with the findings of Romer et al., (20) on school aged children which showed that those who born vaginally after a 12 hours or more course of labor had lower IQ level than those born vaginally after a shorter course of labor. In comparison with children who had been delivered by C.S., who were the more appropriate control group, they had significantly lower intelligence scores which indicated the prolonged and obstructed labor which might adversely affect IQ. In this condition, the cesarean section is preferred and can maintain the children from morbidities and mental sequel and can be performed with safety for mothers and fetuses.

Interestingly, among data presented in (table 3) was birth weight, so the children of the present study were selected to be born within the normal birth weight which should be $2.5 \mathrm{Kg}$ or more 
to exclude the possibility of the low birth weight to be the cause of low intelligence. This confirmed the results of Rahu (21) who stated that in the normal range of birth weight ( $\geq 2500 \mathrm{~g}$ ) every $500 \mathrm{~g}$ increase in birth weight was accompanied by around 0.7 point increase in IQ scores $(P=0.02)$. Also this agreed with the findings of Richards (22), Shenkin (23), and Shenkin (24)

Concerning (Table 4) which showed the distribution of children IQ scores, about two thirds $(65 \%)$ of the children have an average IQ scores, while $8 \%$ only have high IQ scores with a mean score of $9.53 \pm 4.71$. and this could be discussed as according to the IQ scale used in the present study that was developed by Fouad (7), the IQ of the children included in this study were within the normal IQ level.

By looking to (Figure 1); at a primary analysis, it was found that there was no statistical significant difference between children IQ scores of cesarean delivery and natural vaginal delivery groups $(P$. value $=0.286)$. These results agreed with the findings of Khadem ( 5), in which it was found that there was no any statistical significant difference between IQ scores of cesarean delivery and natural vaginal delivery groups (101 versus 100.7).

Regarding (Figure 2); results of the present study demonstrated that there was no relation between mother's educational level and children IQ $(P$. value $=0.130)$, these results agreed and supported the findings of Eide $\boldsymbol{e t}$ al., (25), in which it was found that there were no statistical significant difference between different mother's educational levels and children IQ scores $(P$. value $=0.06)$. On the other hand, these results didn't agree with the findings of Rahu et al., (21)) in which the higher mother's educational level the higher children IQ. Several characteristics of mothers had detrimental effect on their children's mental abilities. Mothers with basic education, had children who scored 5-6 IQ points below of the respective age norms. This study concluded that the most beneficial for children's IQ was to have a married mother with secondary or university education.

By looking to (Figure3); it was found that there was a statistical significant difference between both children of working and non working mothers in which the mean IQ scores were (9.85 for housewives mothers while 8.34 for working mothers) and $(P$. value $=0.05)$. This is may be rendered to that the working mother have no enough time to follow their children and also has their own job stressors. Working mothers found extremely difficult to juggle their jobs and their home life. They often felt overwhelmed and impatient with those around them, especially their children. But housewives mothers have a lot of time to spend with their children which enables them to acquire different skills which subsequently affect their intelligence and academic achievement. These results didn't agree with the results of Kelly, (26), in which it was found that having a working or stay at home mother does not determine a child's academic ability or intelligence.

In a secondary analysis showed in (Table5) using other advanced statistical techniques called (stepwise regression) able to identify variables that could predict the children IQ and at the same time exclude variables that couldn't predict IQ, by using this technique in our study it was found that there were three variables that could predict or affect the children IQ scores which were:

1. Mode of delivery (S.V.D): in this study it was found that the mode of delivery (S.V.D) was the first and strongest predictor of children IQ $(P$. value $=0.001)$, in which it was found that S.V.D was related to a higher intelligence scores. And this confirmed the findings of Seidman,(27)in his study, after adjustment for confounding factors; the IQ score of the C.S. group was 103.7 which were significantly lower than that of spontaneous delivery group with the score of 105.7 .

2.Mother's age: (the second factor could predict children IQ); in the present study mother's age was found to be related to higher intelligence scores but in a direct negative relation $(P$. value $=0.001)$, in other words the higher mother's age the lowest child IQ score and vice versa. This may rendered to great care given to the woman during first pregnancies and good general health in small ages. This is consistent and agreed with the findings of Rahu., (21) who studied "Effect of birth weight, maternal education and prenatal smoking on intelligence at school age" in which it was found that the mean IQ of the children by mother's age were (99.3) for children whose mother's aged (2034 years) and (98.6) for children whose mother's aged $(\geq 35$ years) for male children, while for female children the mean IQ of the children were (102) for children whose mother's aged (20-34 years) and (101) for children whose mother's aged ( $\geq 35$ years). The results of the present study revealed that there were highly statistical significant differences (negative relation) between mother's age and children IQ $(P$. value $=0.001)$; and this couldn't support the findings of Eide ,( 25) in which it was reported that there was a direct positive relation between mother's age and children IQ scores, that means the higher mother's age the higher children IQ scores and vice versa $(P$. value $=0.001)$. 
3. Number of deliveries: (the third factor predicting IQ). The results of the present study showed that there was highly statistical significant difference (direct negative relationship) between number of deliveries and children IQ scores $(\mathrm{P}$. value = 0.001 ) which means the more number of deliveries the lower children IQ scores. That could be explained as multipara woman's general health was deteriorated with multiple pregnancies and weakness of the uterine muscles that impair normal placental circulation. This came in accordance with the findings of Rahu ,(21); who reported that modest effect of deliveries on children intelligence (small advantage of the firstborn over later born) became stronger and statistically significant after adjustment.

\section{Conclusion:}

In the light of the present study findings, it can be concluded that there were no statistical significant difference between children IQ scores based on the mode of delivery $(P=0.286)$.

On the other hand, in the present study by using an advanced statistical technique able to predict the children IQ level, it was found that children IQ levels could be predicted through three variables:

1. Mode of delivery: as it was found that S.V.D. was related to higher IQ scores $(P=0.001)$.

2. Finally, based on our findings the association between cesarean deliveries with better cognitive development in children of pre-school age couldn't be supported.

\section{Recommendations:}

Based on the most important findings of the present study, the following recommendations were suggested:

1. Giving more attention to (S.V.D) through proper management of different stages of labor especially 2 nd stage of labor as it was found that it may be an indicator for higher IQ scores.

2. Encourage the women to use family planning methods to limit number of children as it was found that increasing number of deliveries not only affecting mother's general health status but also may be a cause for lowering children IQ.

3. Increase the sample size in the future studies so that results could be generalized on all people.
1. Gilbert, E.S. (2007): Manual of high risk pregnancy and birth. St. Louis: Mosby, $3^{\text {rd }}$ ed., 36-39

2. Abu El- Ella B.M., (1976): General psychology, Cairo, Ain shams printer. 15-17.

3. Angeja AC, Washington AE, Vargas JE, Gomez R, Rojas I, Caughey AB. (2006): Chilean women's preferences regarding mode of delivery which do they prefer and why? BJOG; 113(11): 1253-8.

4. Animasahun RA; (2003): The Effect of Six Thinking Hats in Enhancing the Decision Making Behaviour of Nigeria Prisoners. Nigerian Journal of Applied Psychology, 7(2): 66-79.

5. Eide M.K., Posner, M.I., \& Hershey, K.L., (2005): Temperament, attention, and developmental psychpathology in D. Ciccetti \& D.J., Cohen (Eds), developmental psychpathology (P.p. 315-342). New York: John Wiley\& Sons.

6. Eric J Dolgin, (2011): Birth traumas. WWW.Osteohome.com

7. Faisal-cury A, Rossimenezs P. (2006): Factors associated with personal preference for cesarean. Revista de Saude Publica; 40(2): P.p. 1-8.

8. Farag S. (1989): factor analysis of attitude sciences, Cairo: Arabic thinking home, 11-18.

9. Fouad N.A, (1991): The moral concepts and how to develop them in the pre- school child, Faculty of Education, el-Minia University, Pp 88-91 \& 205-206.

10. Jimoh MO. (2007): Spiritual Intelligence, Emotional Intelligence and Intelligent Quotient as Predictors of Adjustment to Teaching Profession among the Voluntary Teaching Corps Scheme Employees in Ogun State. M.Ed Dissertation, Unpublished. Ibadan: University of Ibadan, 15-26.

11. John W., Sons LTD. (2002): More IQ testing. Philip Carter and Ken Russell. Pp1-18.

12. Karande, S; Kulkarni, M; (2005): Indian Journal of pediatrics, Poor school performance, Symposium on Developmental and Behavioral disorder-11; Lokmanya Tilak municipal, PP 961-67.

13. Kelly L. McIntosh, William Bauer. (2006): Working mother's vs. stay at home mothers: the impact on children, Marietta College, Masters Examination Committee, P.p. 1-20.

14. Kenny, T.K., Culbertson, J.L., (2003): Developmental screening for preschoolers. In Culbertson JL, Willis DJ, editors. Testing Young Children: A Reference Guide for Developmental, Psycho educatinoal, and 
Psychosocial Assessments. Austin, TX: Pro Ed. P.p. 73-100.

15. Khadem N., Khadivzadeh T. (2010): The intelligence quotient of school aged children delivered by cesarean section and vaginal delivery. Iran J Nurs Midwifery Res; 15(3): 135140.

16. Meikle SF, Steiner CA, Zhang J, Lawrence WL. (2005): A national estimate of the elective primary cesarean delivery rate. Obstet Gynecol; 105(4): 751-6.

17. Rahu K. , Mati Rahu, Helle Pullmann , Jüri Allik. (2010): Early Human Development, National Institute for Health Development, the Estonian Centre of Behavioural and Health Sciences, Estonia, 86: P.p. 493-497.

18. Richards M, Hardy R, Kuh D, Wadsworth MEJ. (2001): Birth weight and cognitive function in the British 1946 birth cohort: longitudinal population based study. Br Med J Jan; 322(7280):199-203.

19. Roemer FJ, Rowland DY, Nuamah IF. (1991): Retrospective study of fetal effects of prolonged labor before cesarean delivery. Obstet Gynecol; 77(5): Pp 653-8.

20. Seidman DS, Laor A, Gale R, Stevenson DK, Mashiach S, Danon YL. (1991): Long-term effects of vacuum and forceps deliveries. Lancet; 337(8757): 1583-5.

21. Semel E, Wiig E, Secord W. (2000): Clinical Evaluation of Language Fundamentals. The Psychological Corporation. San Antonio UK, $3^{\text {rd }}$ ed. (CELF-3UK), P.p.3-16.

22. Shenkin SD, Starr JM, Deary IJ. (2004): Birth weight and cognitive ability in childhood: A systematic review. Psychol Bull Nov; 130(6):989-1013.John W., Sons LTD. (2002): More IQ testing. Philip Carter and Ken Russell. Pp1-18.

23. Shenkin SD, Starr JM, Pattie A, Rush MA, Whalley LJ, Deary IJ (2001): Birth weight and cognitive function at age 11 years: the Scottish Mental Survey 1932. Arch Dis Child Sep 2001; 85(3):189-95.

24. Stemberg, R. J., \& Detterman, D. K. (Eds.). (2002): what is intelligence? Contemporary viewpoints on its nature and definition. Norwood, NJ: Ablex.

25. Tork J. Eesti laste. (2005): intelligents /Intelligence of Estonian children/. Tartu: Koolivara, 81-95.

26. Yavuzer, H. (2000): Child with His/Her Drawings [Resimleriyle Çocuk]. Remzi Kitabevi, BaskQ, 12-23.
27. Zohar D, Marshall I (2000): Spiritual Intelligence, the Ultimate Intelligence SQ. New York: Bloomsbury, 33-36 